\title{
Beyond the garden: The complexity of "global and individual living" at the heart of the international commitment towards a healthy, more resilient and fairer society
}

\author{
Luca Dimasi \\ University of Bologna, Bologna, Italy \\ E-mail: luca.dimasi@unibo.it
}

Received 18 October 2021

Accepted 29 December 2021

\begin{abstract}
.
BACKGROUND: The right to fully enjoy the highest possible state of health is certainly nothing new in the agenda of the world's governments, and yet today it becomes a top priority not just in the restructuring of the health care system, but also in the promotion of multi-sector policies aimed at fostering and safeguarding the potential of every individual to achieve what could be defined, in general terms, as "common good".

OBJECTIVE: The current paper aimed at singling out the most useful strategies to promoting and achieving a healthy, more resilient and fairer society.

METHODS : Starting from principles 1 and 14 of the Declaration of Rome, the aim was to analyse and develop the concepts of resilience and health, questioning their possible future variations against the background of the current health emergency and the increasingly radical widespread use of new technologies as universally-applied and cross-sectional tools for human progress. RESULTS: The "health for all" objective can only be achieved if we act on three key aspects: 1 . Adding life to years; 2 . Adding life to life; 3. Adding years to life.

CONCLUSIONS: Each individual should raise their health awareness as a key resource to leading a fulfilling existence and to developing the required qualities to fully tap into health possibilities - whether integral or residual - to tackle life.
\end{abstract}

Keywords: Health, resilience, global development, new technologies, equality, inclusion, cooperation, subsidiarity

\section{The Declaration of Rome}

"We, Leaders of G20 and other States, in the presence of the Heads of international and regional organisations meeting at the Global Health Summit in Rome, May 21, 2021, having shared our experience of the ongoing global COVID-19 pandemic, and welcoming relevant work in this regard, including that presented during the pre-Summit, today." 
This is the solemn opening of the Rome Declaration, the final document of the Global Health Summit held in Rome on 21 May 2021.

What the paper clearly shows is the need to foster international cooperation as much as we possibly can in order to tackle the countless challenges of the times we live in, so not just the pandemic but also global inequalities and climate change. In other words, the Rome Declaration - defined by the President of the European Commission, Ursula von der Leyen, as a "historic" and "revolutionary" act - highlights the importance to pursue a so-called One Health ${ }^{1}$ approach, extending it to the protection of the environment and the implementation of technological and IT potential to guarantee the integrity of our planet and, consequently, the health of the entire world population.

The cross-sectional commitment, solemnly stated in the paper in question, is thus a resilient and coordinated response, first and foremost for a recovery - as inclusive as possible - from COVID-19. Besides a short-term vision, the purpose of the Rome Declaration, as mentioned above, is to look to the future with regard to prioritising the implementation of adequate measures to safeguard public health.

Achieving such goals means that all countries involved should abide by a set of principles clearly listed within the Declaration, thus representing the commitment of single national players to achieving tangible progress towards actions that will be promoted up until the next G20 Summit and beyond.

This paper will examine, in particular, Principles 1 and 14.

\section{Principles 1 and 14}

The first principle focuses on three important goals: 1. Support and enhance the existing multilateral health architecture; 2 . Support the achievement of the SDGs; 3 . Support the goal of a sustainable, inclusive, and resilient recovery.

Once again, it is noted how promotion and achievement of a healthy life and global wellbeing must go hand in hand with the protection of environmental and social conditions we all live in.

However, the right to enjoy the highest possible level of health is nothing new in the world governments' agendas. Indeed, already back in 1977, the Third Global Health Summit defined health as "a basic human right and a worldwide social goal, and that it is essential to the satisfaction of basic human needs and the quality of life" and stated that "the main social target of governments and WHO in the coming decades should be the attainment by all the citizens of the world by the year 2000 of a level of health that will permit them to lead a socially and economically productive life"2.

The urgency of such goal, then as now, was emphasized by two important facts: 1 . Despite funds allocated to the health sector and the development of new drugs and medical technologies, people's level of health is far lower compared to what it should be; 2. Despite the overall high level of development and the scientific, economic and cultural level of most countries, the big challenge against health inequalities is yet to be overcome.

\footnotetext{
${ }^{1}$ One Health - first defined in 2004 during the conference organised by the Wild Conservation Society (Manhattan principles) - is a holistic vision to achieve global health based on the integration of several disciplines. It deals with the needs of the most vulnerable people on the basis of the close relation amongst their health, that of animals and the environment they live in, considering the broad spectrum of determinants emerging from it. One Health can be considered a harbinger of important, albeit rarely implemented, documents of world health strategies put forward over the years by the World Health Organization. They include the Alma Ata Declaration of 1978, the Ottawa Charter of 1986, Health 2020 of 2012, and more recently, the Shanghai Declaration of 2016.

${ }^{2}$ WHO Resolution 30.43 .
} 
All this requires, especially in the light of the current pandemic crisis, a profound change in the health process development of each country, through a cross-sectorial action, as reiterated in the Rome Declaration, in three key sectors: restructuring the healthcare system, lifestyle and health models and lastly risk factors for both health and the environment.

Furthermore, "Health for Everyone" necessarily entails equal treatment for all. This means that existing health inequalities amongst countries and within each country should be reduced to a minimum.

Everyone should attach a positive value to health, which should allow people to fully enjoy their physical, mental and emotional abilities. Promoting health and disease prevention should thus be incentivized.

Such target - where single individuals are to achieve the goal of health for all - can be attained, though, only through a coordinated action amongst all sectors involved; health authorities can only deal with some of the problems to be solved and multi-sectorial cooperation is the only means able to effectively guarantee basic conditions for health, promotion of health policies and risk reduction in the physical, economic and social environment we all largely rely on. Therefore it is necessary, first of all, to adopt healthy lifestyles through general policy-making compatible with the needs of health promotion and protection.

All this must be done - and this leads us to the analysis of principle 14 - considering also that the main responsibility for the achievement of the above-mentioned goals is, once again, beyond the health sector and must be fully recognized at all governmental as well as social levels, so that health promotion and strengthening of general resilience, even towards possible future health crises, take into account all such aspects of life (so called social determinants) that do represent a pre-requisite for health.

After all, the pandemic risk does not constitute the only health issue that, in the near future, world governments will have to face. Non-transmissible diseases, mental health and food will be just a few of the challenges where we do not wish to be found wanting.

In this respect, all States should primarily be committed to guaranteeing fairness also in the health sector that, as stated within Principle 14, takes into account - amongst other factors - age and gender.

We are only reiterating, therefore, what was already in embryo in the definition of health provided by the World Health Organization, as the state of complete physical, mental, and social wellbeing and not merely the absence of disease or infirmity. Such concept implying health as a positive condition concerning individuals in their entirety and unity is indeed that everybody - regardless of their economic, social, gender and age status etc. - can achieve a state of wellbeing by tapping into their functional abilities ${ }^{3}$.

Nevertheless, all too often, most health programmes focus on diseases meant as biological deviation from the norm, rather than the unavoidably relational dimension of health.

In other words, to achieve health for all, building and/or implementing new structures developing health chances for all individuals is necessary, while removing any obstacle preventing people from making use of the potential already available to them.

Additionally, it is thus required, as previously mentioned, that individuals themselves should become more aware of health as an important resource to lead a fulfilling life and to develop the necessary qualities to make full use of health possibilities - whole or residual - to face life.

\footnotetext{
${ }^{3}$ The positive concept of health, meant as a "condition of full physical, mental and social wellbeing" and the growing interest towards social implications of chronic diseases and infirmity, also due to an increase of such conditions in the population, leads us, as a matter of fact, to the need to go beyond the notion of healing as mere absence of disease, favouring a more general "complexity of living", i.e. something that comes after healthcare intervention, but inherently related to a renewed definition of health. The latter, in broader terms compared to that drawn up in 1948 by the World Health Organisation, also expresses the ability to self-adapt and self-manage in a relational perspective, within which even the "differently healthy" are included.
} 
It is, therefore, of paramount importance to acknowledge that, sometimes, part of the population may not be actually able to truly tap into its abilities, so some infirmities or functional limitations - as is often the case with many elderlies - can result from such shortcomings.

Not only in old age do many encounter serious obstacles in improving and preserving their health. Just think about single parents with small children, night shift workers, immigrants and patients who suffer from mental disorders. In all these cases, individuals are often excluded from normal social interaction or do not have the time or the economic means to engage in recreational activities with ensuing impacts on the proper development of their health potential.

The current health emergency has greatly exacerbated these issues, putting a strain on the relationship between individuals and the community. Forced isolation has often created a real vacuum in human existence which has hit all sections of the population across the board [1]. Not only the elderly and other so-called fragile groups of people who have suffered from loneliness but also youngsters and children who, in many cases, felt disoriented, lonely and with what for some represented a real "internal chaos"4.

This is why in the Rome Declaration the term "resilience" recurs several times. As a matter of fact, the pandemic has forced us to seriously ponder on the topic of resilience in its "transformative" meaning, which means resuming our interrupted path but rethinking the choices underpinning our development instead of going back to business as usual.

This is the very paradigm that Principle 14 of the Rome Declaration refers to. In its opening lines, it states that the achievement of what in general terms could be defined as "common good" can only be obtained through cooperation amongst institutions, intermediate bodies and communities. Good subsidiarity - Carla Colicelli writes - "can mitigate problems arising from the lack of coordination between territories and levels of government and it can also alleviate loneliness of the fragile, the disabled, families with children and the elderly. Subsidiarity also refers to global common policies when facing pandemic challenges, wars and poverty, focussed on the wellbeing of all countries and across the planet" [1].

Once again, the message is crystal clear: ensuring fairness would not be possible without acting on the dynamics connecting individuals to their social fabric.

This amounts to saying that the interaction between disabled or somehow fragile people and "chronically normal people" [2] can only happen where it is revisited also from an affected person's point of view. In this sense, the idea, underpinning the recovery, of taking back responsibility for our health, recovering, from time to time, the specific sense of our existence in the different material circumstances of our lives (job, income, home, socialization, everyday life, etc.) undoubtedly reconfirms the importance of the subjective factor or subjectivity as such. It also reiterates the way in which the dimension of the individual experience takes centre stage in rebuilding the link between the possibility of real integration and the value of illness as recognition of diversity.

"Giving meaning to an idea of citizenship of [fragile] individuals while supporting them in their recovery, thus means helping them, above all, to fulfil their lives in a given social context" [3].

But at the same time, it is also important to understand that "society, from community level up, must be mobilised and characterised by the transformation into a strategy envisaging a bidirectional, and thus dialectic, movement" [4].

This is not enough, though. No policy, no legislative change and no new regulation can be usefully adopted "without ensuring [as just mentioned] the authentic participation [of involved parties] in the defence of their rights" [5].

\footnotetext{
${ }^{4}$ This can be understood both as "emotional chaos" in relation to physical and relational suffering and internal loneliness and as "chaos of rationality" in relation to existential, economic and value problems that inevitably worsen in a crisis.
} 
In other words, this means that ensuring the disabled and, in more general terms, the so-called fragile people can have access to the necessary support to overcome any barrier hindering their chance to live in the community and enjoy the same opportunities as others, as a matter of fact, is not the only viable path forward [5]. Future inclusion policies must indeed entail and promote the active involvement of the very people such policies are designed for.

To this end, the UN Convention of the Rights of Persons with Disabilities ${ }^{5}$ aimed at making mandatory the consultation of persons with disabilities and, with them, all the organizations representing them; Art. 4.1 states that "in the development and implementation of legislation and policies to implement the present Convention, and in other decision-making processes concerning issues relating to persons with disabilities, States Parties shall closely consult with and actively involve persons with disabilities, including children with disabilities, through their representative organizations."

Moreover, it is noteworthy that the document does not include a clear definition of disability, but it rather provides a broader and more inclusive description. "Persons with disabilities", it reads, "include those who have long-term physical, mental, intellectual or sensory impairments which in interaction with various barriers may hinder their full and effective participation in society on an equal basis with others".

That is to say the real problem is not quantifying and describing impairments and collecting information on potential barriers but rather defining a person's care needs. Thus, we must ask ourselves what an individual's objectives are and what is needed so that that person can express his/her full potential in society while enjoying the same opportunities available to others [6].

This will be the greatest challenge in the near future, along with adequately adjusting these principles to the role modern technologies can play in the development of more advanced forms of wellbeing, social cohesion, cooperation, peaceful coexistence and, last but not least, respect for human dignity.

Thus, it will be even more urgent and necessary to focus on the values underpinning the use of technology through the examination of the relationship between the latter and a different and deeper resilience compared to that we could envisage before the current health emergency.

"Technology - as a means of transformative resilience thanks to which we can/must imagine a connection between individual freedom needs and community requests as well as an instrument that will enable us to tackle resource scarcity and inequality issues - is the new hallmark", Paolo Benanti, JeanPierre Darnis and Antonella Sciarrone observe [7].

There is clearly a huge potential, but as the authors highlight, we need to be careful, since digital means cannot fully replace the analogue experience, even if they might look very similar. Furthermore, so far, the digitalization of relationships has not been uniform, but it has rather followed, often accepting it, the trend of social inequalities.

Faced with this scenario, we must then conceive and create technology according to a development model not focusing on technical capacity but rather on human beings as the core of the entire reflection and as the end qualifying such progress; essentially, a global, comprehensive, plural, fruitful and "kind" development model, "[...] global, that is for all women and for all men, not only just for some or some groups (divided by gender, language or ethnicity); comprehensive, that is concerning a woman or a man in their entirety; [...] plural, that is paying attention to the social context in which we live, respectful of human plurality and different cultures; [...] fruitful, that is capable of laying the foundations for future

\footnotetext{
${ }^{5}$ The Convention of the Rights of Persons with Disabilities was adopted by the UN General Assembly in December 2006. Available from: https://www.un.org/disabilities/documents/convention/convoptprot-e.pdf.
} 
generations instead of being short-sighted and aimed at today's resources without ever looking to the future; [...] kind, that is respectful of the planet hosting us (our common home), of its resources and its living species".

This is the only way to guarantee fairness in health, reducing the current gap between health situations in various countries and groups within them, but also to act on three other aspects characterising the goal of health for all.

\section{Conclusion}

By way of conclusion, I would like to reiterate them:

(1) Adding life to years, ensuring the full development and use of complete or residual physical and mental abilities of all to allow everyone to enjoy life to the full and in good health;

(2) Adding health to life, reducing illnesses and infirmity;

(3) Adding years to life, reducing premature deaths thus improving average life expectancy [8].

\section{Conflict of interest}

None to report.

\section{References}

[1] Colicelli C, Salute, comunità e sussidiarietà ai tempi della pandemia. In: Caporale C, Pini A, editors. Pandemia e resilienza. Rome: Edizioni Consiglio Nazionale delle Ricerche; 2020, 47.

[2] Deegan PE, Recovery, Rehabilitation and the Conspiracy of Hope. Brisbane; 1996. Available from: http://www.patdeegan. com/pat-deegan/lectures/conspiracy-of-hope.

[3] Mezzina R, Tra soggettività e istituzioni. Da Franco Basaglia alla recovery. In: Maone A, D’Avanzo B, editors. Recovery. Nuovi paradigmi per la salute mentale. Milan: Raffaello Cortina Editore; 2015, 213.

[4] Basaglia F. Potere e istituzionalizzazione Scritti I, 1953-1968. Dalla psichiatria fenomenologica all'esperienza di Gorizia. Torino: Einaudi; 1982. p. 283.

[5] President's New Freedom Commission on Mental Health, Achieving the Promise: Transforming Mental Health Care in America. 2003. Available from: https://sprc.org/sites/default/files/migrate/library/freedomcomm.pdf.

[6] Amering M, Schulze M, Recovery e diritti umani. In: Maone A, D’Avanzo B, editors. Recovery. Nuovi paradigmi per la salute mentale. Milan: Raffaello Cortina Editore; 2015, 185.

[7] Benati P, Darnis JP, Sciarrone Alibrandi A, Per una resilienza con la tecnologia. In: Caporale C, Pini A, editors. Pandemia e resilienza. Rome: Edizioni Consiglio Nazionale delle Ricerche; 2020, 120.

[8] Centro Italiano Studi Indagini Roma, Gli obiettivi della salute per tutti. Rome; 1986, 25. 